\title{
Is it important to take the co-occurrence of obesity and cigarette smoking into account in brain imaging studies in major depressive disorder?
}

\author{
Dursun Hakan Delibas ${ }^{1 \oplus}$, Pelin Kurtgoz Zorlu' ${ }^{\circledR}$, Emel Pasa Baskin $^{\circledR}$, Emre Bora ${ }^{2,3}$, \\ Zehra Hilal Adibelli ${ }^{\circledR}{ }^{\oplus}$, Nabi Zorlu ${ }^{5}$ \\ 'Bozyaka Training and Research Hospital, Department of Psychiatry, Izmir - Turkey \\ ${ }^{2}$ Dokuz Eylul University, School of Medicine, Department of Psychiatry, Izmir - Turkey \\ ${ }^{3}$ University of Melbourne and Melbourne Health, Melbourne Neuropsychiatry Centre, Department of Psychiatry, Victoria - Australia \\ ${ }^{4}$ Bozyaka Training and Research Hospital, Department of Radiology, Izmir - Turkey \\ ${ }^{5}$ Katip Celebi University Ataturk Training and Research Hospital, Department of Psychiatry, Izmir - Turkey
}

\begin{abstract}
Objective: To date, a small number of studies have investigated cortical thickness, cortical surface area, and subcortical volume abnormalities in first-episode, untreated patients with Major Depressive Disorder (MDD). The findings of previous studies are not entirely consistent. Previous studies did not match first-episode, untreated patients with MDD to controls regarding body mass index (BMI) and smoking, which could contribute to the inconsistency of results. The aim of the current study was to examine whether morphological abnormalities are present in first-episode and untreated MDD patients in comparison with well-matched controls, particularly concerning BMI and smoking status.

Method: Twenty first-episode, untreated patients with MDD were enrolled in the study along with 20 healthy controls (HC) matched for age, education, sex, BMI and smoking status. Thickness and area of the cortex and subcortical volumes were measured using surface-based morphometry implemented with Freesurfer (v5.3.0).

Results: There were no significant differences in cortical thickness, surface area, and subcortical volumes between the firstepisode, untreated patients with MDD and HC groups.

Conclusion: This study provides evidence that cortical thickness, cortical surface area, and subcortical volumes might be normal in first-episode untreated patients with MDD in comparison with well-matched controls, particularly for BMI and smoking status.
\end{abstract}

Keywords: Cortical thickness, major depressive disorder, structural imaging, subcortical volume

\section{INTRODUCTION}

Major Depressive Disorder (MDD) is one of the most common mental disorders and is a leading cause of disease burden worldwide (1). Nevertheless, despite the increasing prevalence and disease burden of MDD, the neurobiological mechanisms underlying the disorder remain unclear.

How to cite this article: Delibas DH, Kurtgoz Zorlu P, Pasa Baskin E, Bora E, Adibelli ZH, Zorlu N. Is it important to take the co-occurrence of obesity and cigarette smoking into account in brain imaging studies in major depressive disorder? Dusunen Adam The Journal of Psychiatry and Neurological Sciences 2019;32:121-8.

Correspondence: Dursun Hakan Delibas, Bozyaka Training and Research Hospital, Department of Psychiatry, Saim Cikrikci Cad., No: 59, 35170, Karabaglar, Izmir - Turkey

Phone: +90 2322505050 - 6080 E-mail: drdelibas@gmail.com

Received: December 04, 2018; Revised: January 07, 2019; Accepted: March 02, 2019 
Recent neurobiological models suggest that impaired neuroplasticity and neurogenesis due to alterations in neurotrophic factors, increased glucocorticoid exposure or chronic inflammation play a prominent etiologic role in depression (2). Therefore, neuroimaging studies can provide important insight into the neurobiology of MDD. Available evidence suggests that MDD might be associated with overall reductions in regional subcortical and cortical volume (3-9) and abnormalities in cortical thickness and surface area (10). However, the effect sizes of these changes are small to modest and there is a considerable heterogeneity across studies. For example, some surface-based morphometry (SBM) studies have found increased cortical thickness $(11,12)$, whereas others reported lower $(10,13-15)$ or similar $(16,17)$ cortical thickness in patients with MDD compared to healthy controls. These inconsistent findings might be at least partly attributed to the effects of medication (8) or the influence of chronic or recurrent episodes (18). Therefore, first-episode studies in unmedicated patients with MDD are important to reveal structural brain findings that are not confounded by either potential neurotoxic effects of prolonged stress and recurrent episodes or neuroprotective effects of antidepressant medications.

To date, a small number of SBM studies have investigated cortical thickness abnormalities in firstepisode, untreated patients with MDD. Unlike the findings of most of the studies in recurrent MDD, a number of them found increased $(11,12,19)$ or both increased and decreased $(20,21)$ cortical thickness in first-episode, untreated patients with MDD compared to controls. However, a few other studies reported decreased $(22,23)$ or preserved $(24)$ cortical thickness in this patient group. Similar to cortical thickness studies, the findings of previous studies that examined subcortical volume alterations in various regions in first-episode, unmedicated MDD (mostly hippocampus and amygdala) are not entirely consistent. Meta-analyses observed smaller hippocampal and amygdala volumes in patients with first-episode MDD (7,25). However, recent studies reported no difference in hippocampus and amygdala volumes $(22,24,26)$ and in other subcortical structures in $(22,24,27)$ in first-episode patients with MDD.

There are a number of potential factors that can contribute to inconsistent findings across studies in MDD. While some factors such as illicit drug use and history of significant co-morbid medical disorders are frequently excluded in brain imaging studies in MDD, the effects of obesity and cigarette smoking on cortical and subcortical changes have been generally neglected.
Obesity is associated with depression even in early stages of life (28). Chronic stress leads to resistance to leptin receptors, contributing to obesity (29). Both active and passive smoking often leads to respiratory symptoms (30). Respiratory symptoms, obesity, and depression are mediated by proinflammatory cytokines (31) and neuropeptide Y (32). Obesity and cigarette smoking are more prevalent among patients with MDD compared to the general population $(33,34)$ and are reported to alter the structural changes in MDD patients $(35,36)$. Moreover, obesity and smoking also modify subcortical volumes (36-38). It is therefore of importance to take the co-occurrence of obesity and cigarette smoking into account in brain imaging studies in MDD. However, no previous studies matched firstepisode, untreated patients with MDD to controls on body mass index (BMI) and smoking, which could contribute to the inconsistency of results.

Our hypothesis is that smoking status and obesity are important confounding factors that should be considered in imaging studies in untreated first-episode depression patients. The aim of the current study was to examine whether morphological abnormalities are present in first-episode and untreated MDD patients, in comparison with well-matched controls, particularly for BMI and smoking status.

\section{METHOD}

Twenty first-episode, untreated patients with MDD were enrolled in the study along with 20 healthy controls (HC). All MDD patients were diagnosed using the Structured Clinical Interview for DSM-IV (SCID-I) (39) and met the following inclusion criteria: fulfilling DSM-IV criteria for major depressive disorder; aged 18-65; no comorbid Axis I psychiatric disorders, including anxiety disorders; currently experiencing an episode of depression with a score of at least 20 (indicating at least moderate severity) on the 17-item Hamilton Depression Rating Scale (HDRS-17) (40). The healthy group consisted of individuals with no current or past Axis I disorder as assessed by the SCID.

Exclusion criteria for all participants included: $<18$ years of age; any MRI contraindications; pregnancy; history of head injury or neurological disorder; abuse of or dependence on alcohol or other substances; any family history of bipolar or psychotic disorder in their firstdegree relatives and any concomitant medical disorder.

MDD patients and control subjects were matched for sex, age, years of education, handedness (all were right handed), smoking status, and BMI. Non-smoker 
MDD patients as well as HCs had no smoking history. Smoking severity was assessed with the Fagerström Test for Nicotine Dependence (FTND) (41). BMI was determined as weight in kilograms divided by height squared in meters. All participants underwent baseline clinical assessment and an MRI scan within $48 \mathrm{hrs}$ of initial contact.

All participants gave written informed consent to participate in the study. This study was approved by the local research and ethics committee.

\section{Measures}

Hamilton Depression Rating Scale (HDRS-17): This scale, which measures the level and severity of the patient's depression, was developed by Hamilton (40). This scale has been validated for Turkish society (41).

Fagerström Test for Nicotine Dependence (FTND): This test was developed by Karl O. Fagerström (42) in order to determine the level of physical dependence on smoking and consists of six items. As the level of addiction to smoking rises, the score from the test increases. The validity and reliability study of the test in the Turkish language was performed by Uysal et al. (43).

\section{MRI Acquisition}

All MRI scans were performed on a $1.5 \mathrm{~T}$ Achieva MR imager (Philips Medical Systems, Eindhoven, Netherlands) with a standard quadrature head coil. All subjects were scanned with a $3 \mathrm{D}$ T1-weighted turbo gradient echo sequence with SENSE using the following parameters: coronal orientation, matrix $256 \times 256,1 \times 1$ $\mathrm{mm}^{2}$ in-plane resolution, slice thickness $1 \mathrm{~mm}$, TE/ $\mathrm{TR}=5.6 / 12 \mathrm{~ms}$, flip angle $\alpha=19^{\circ}$. All scans were inspected to check for motion artifacts and to rule out gross neuropathology.

\section{Cortical Thickness and Surface Area Analysis}

T1 images were analyzed using the FreeSurfer software package (version 5.3.0, http://surfer.nmr.mgh.harvard. $\mathrm{edu}$ ), which is freely available online. Imaging processing procedures were based on previous reports $(44,45)$. Briefly, processing steps included motion correction, removal of non-brain tissue, transformation to Talairach-like space, segmentation of subcortical gray/white matter tissue, intensity normalization, tessellation of the gray matter-white matter boundary, automated topology correction, and surface deformation. Cortical surfaces then underwent inflation, registration to a spherical atlas, and automatic identification of gyral and sulcal regions. Cortical thickness was measured by averaging the distance between the pial surface and grey-white surface. Surface area for each vertex was calculated as the average of the surrounding triangles (46).

Based on previous studies $(10,47)$, we selected the bilateral fusiform gyrus, rostral anterior cingulate cortex, insula, medial orbitofrontal cortex, rostral middle frontal cortex, and superior temporal cortex as regions of interests (ROIs) for additional analysis of cortical thickness.

\section{Subcortical Volume Analysis}

Left and right hippocampus, amygdala, thalamus, caudate, putamen, pallidum and nucleus accumbens volumes and intracranial volume (ICV) were calculated by the automated procedure for volumetric measures of brain structures implemented in FreeSurfer for further statistical analysis.

\section{Statistical Analysis}

Cortical thickness and area maps were smoothed with a full-width half-maximum Gaussian kernel of $15 \mathrm{~mm}$ to ensure a well-powered cross-sectional cortical thickness study because of our modest sample size (48). FreeSurfer's Query, Design, Estimate, Contrast (QDEC) tool was used to test for cortical thickness and surface area differences between MDD and healthy controls. A general linear model was used to identify betweengroup differences in thickness and area estimates with age and sex as covariates of no interest. We used an uncorrected threshold of $\mathrm{p}<0.05$ for initial vertex-wise comparisons. Thereafter, multiple comparisons were corrected with a Monte Carlo Simulation using a threshold of $1.3(\mathrm{p}<0.05)$. All analyses were performed for the right and left hemispheres separately.

The 14 subcortical structure volumes and ICV were imported into SPSS 16.0 for statistical analyses. A GLM was used to analyze subcortical volume differences between groups, with sex as categorical predictor and age and ICV as continuous predictors.

Demographic and clinical characteristics were assessed for the normality of their distribution using Kolmogorov-Smirnov normality test. Parametric and non-parametric tests were used as appropriate. For all analyses, the level of significance was $p<0.05$. Statistical analysis was performed using the Statistical Package for Social Sciences (SPSS, v16.0).

\section{RESULTS}

Clinical and demographic characteristics of the sample are described in Table 1. There were no significant 
differences between the groups in age, sex, BMI, smoking status, or years of education.

There were no significant differences in cortical thickness and surface area between the first-episode, untreated patients with MDD and HC groups. There were also no significant differences in mean cortical thickness values of cortical ROIs between groups (Table 2).

There were no significant differences in subcortical volumes between the first-episode, untreated patients with MDD and HC groups at a significance level of $\mathrm{p}<0.05$ (uncorrected) (Table 3 ).

No correlations were found between the mean cortical thickness value of cortical ROIs or subcortical volumes and the clinical characteristics within MDD group.

\section{DISCUSSION}

Finding no significant difference in cortical thickness between the first-episode, untreated patients with MDD

Table 1: Demographic and clinical characteristics

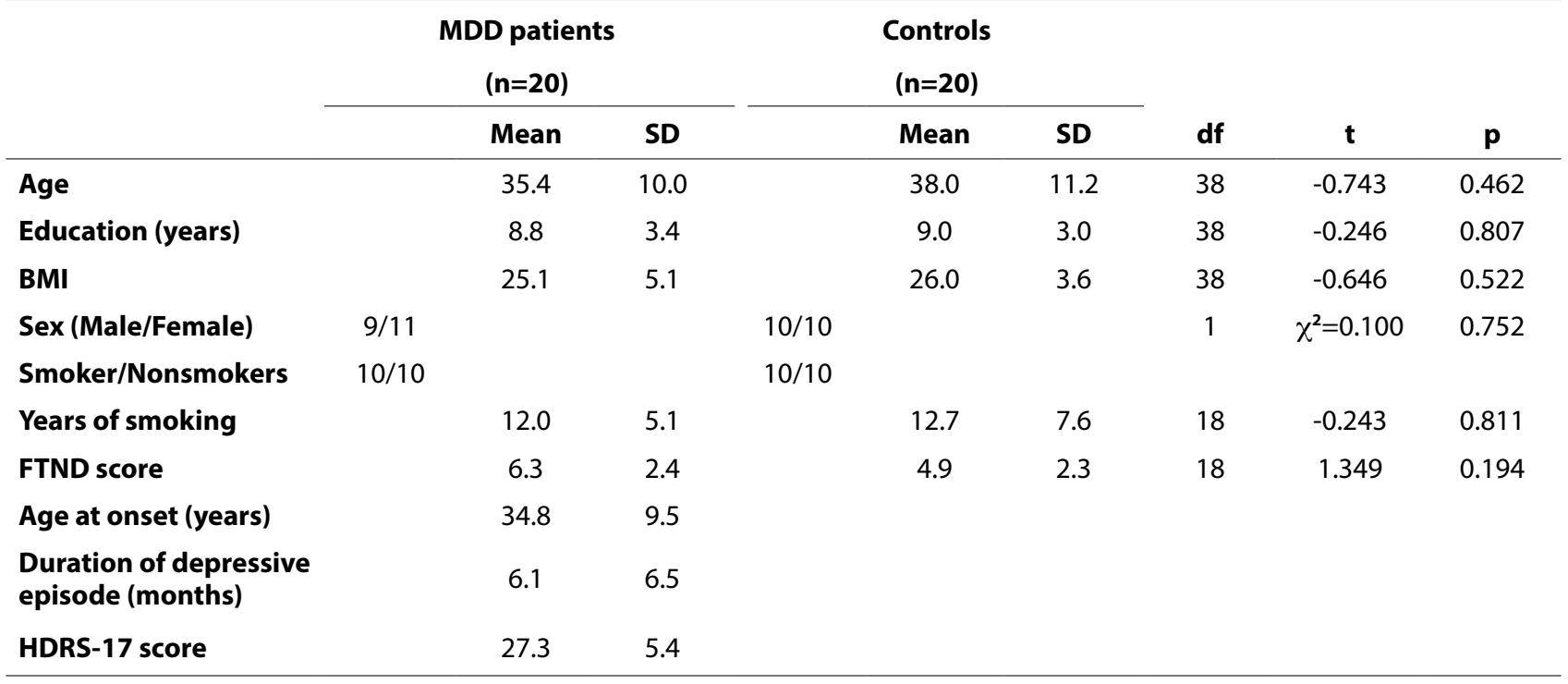

Data are presented as mean \pm standard deviation unless otherwise indicated.

MDD: Major depressive disorder, BMI: Body mass index, HDRS: Hamilton depression rating scale, FTND: Fagerström test for nicotine dependence, t: Student t test

Table 2: Mean cortical thickness values of cortical ROls

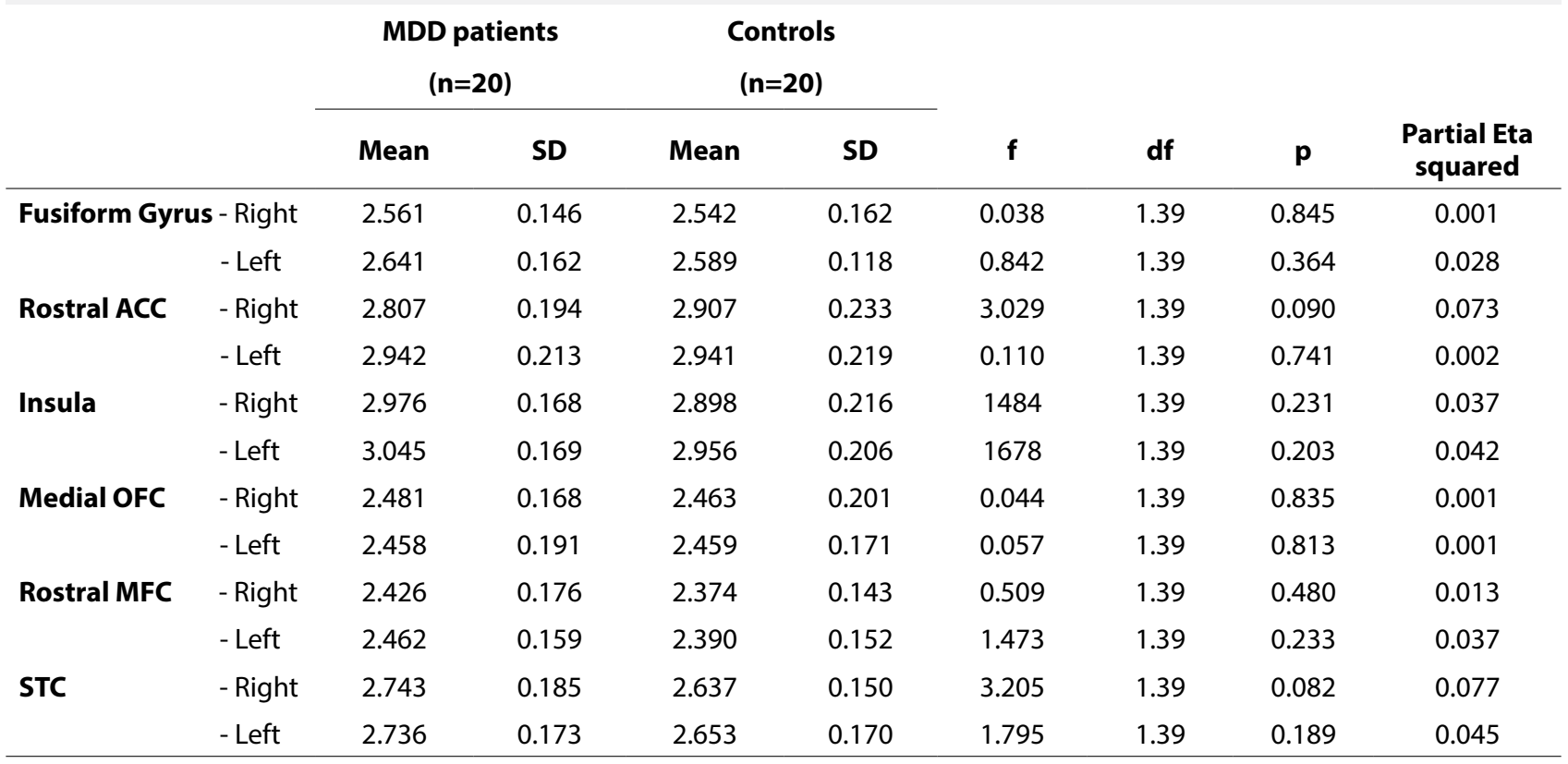


Table 3: Subcortical volumes

\begin{tabular}{|c|c|c|c|c|c|c|c|c|c|}
\hline \multirow[b]{2}{*}{ Hem. } & \multirow[b]{2}{*}{$\begin{array}{l}\text { Subcortical } \\
\text { Segmentations }\end{array}$} & \multicolumn{2}{|c|}{ MDD group $(n=20)$} & \multicolumn{2}{|c|}{ Controls $(n=20)$} & \multirow[b]{2}{*}{ f } & \multirow[b]{2}{*}{ df } & \multirow[b]{2}{*}{$\mathbf{p}$} & \multirow[b]{2}{*}{$\begin{array}{l}\text { Partial Eta } \\
\text { squared }\end{array}$} \\
\hline & & Mean & SD & Mean & SD & & & & \\
\hline \multirow[t]{7}{*}{$\mathbf{L}$} & Hippocampus & 4.119 & 379 & 4.189 & 411 & 0.663 & 1.39 & 0.421 & 0.019 \\
\hline & Amygdala & 1.410 & 189 & 1.388 & 194 & 0.068 & 1.39 & 0.795 & 0.002 \\
\hline & Caudate & 3.238 & 333 & 3.251 & 414 & 0.205 & 1.39 & 0.653 & 0.006 \\
\hline & Putamen & 4.930 & 623 & 4.955 & 663 & 0.626 & 1.39 & 0.434 & 0.018 \\
\hline & Pallidum & 1.343 & 235 & 1.379 & 202 & 0.600 & 1.39 & 0.444 & 0.017 \\
\hline & Accumbens & 459 & 84 & 459 & 71 & 0.245 & 1.39 & 0.624 & 0.007 \\
\hline & Thalamus & 8.007 & 853 & 7.917 & 828 & 0.152 & 1.39 & 0.669 & 0.004 \\
\hline \multirow[t]{7}{*}{$\mathbf{R}$} & Hippocampus & 4.188 & 420 & 4.136 & 321 & 0.085 & 1.39 & 0.772 & 0.002 \\
\hline & Amygdala & 1.461 & 173 & 1.485 & 177 & 0.499 & 1.39 & 0.484 & 0.014 \\
\hline & Caudate & 3.172 & 405 & 3.264 & 367 & 1.218 & 1.39 & 0.277 & 0.034 \\
\hline & Putamen & 4.848 & 545 & 4.776 & 593 & 0.005 & 1.39 & 0.943 & 0.001 \\
\hline & Pallidum & 1.349 & 160 & 1.375 & 172 & 1.120 & 1.39 & 0.297 & 0.031 \\
\hline & Accumbens & 461 & 84 & 484 & 96 & 2.336 & 1.39 & 0.135 & 0.063 \\
\hline & Thalamus & 6.944 & 559 & 6.938 & 705 & 0.021 & 1.39 & 0.887 & 0.001 \\
\hline
\end{tabular}

Data are presented as mean \pm standard deviation, Hem.: Hemisphere

MDD: Major depressive disorder, Hem: Hemisphere, L: Left, R: Right, f: A general linear model with age and sex as covariates

and $\mathrm{HC}$ groups is consistent with findings of one previous study (24) but not with others (11,21-23). It is important to note that smoking status and BMI were not controlled in the previous studies. Thus, different results might be partly due to differences in BMI and smoking status between the studies. For example, studies in cigarette smokers examining brain cortical thickness, which is considered to be more sensitive to environmental factors than cortical volume (49), have found reduced thickness of the orbitofrontal cortex (OFC) (50,51), insula, middle temporal gyrus, anterior cingulate cortex, inferior parietal lobule, parahippocampus (51) and bilateral frontal and temporal cortices (52) compared to non-smoker individuals in the community. Similarly, BMI was also found to be negatively associated with cortical thickness in healthy volunteers $(53,54)$. Given that cigarette smoking and obesity are highly prevalent in MDD $(33,34)$, it is possible that some of the differences in cortical thickness between MDD and controls found in previous studies, particularly cortical thinning, may be partly explained by cigarette use and obesity.

There are several other possible explanations for finding no significant difference in cortical thickness between the two groups. One possible reason for the current negative findings could be that the pathological changes may be too subtle to be detected with our sample size or technique during the first depressive episode. Second, cortical thickness might be normal in first-episode patients and change during the course of the disease or with the recurrence of episodes. However, without longitudinal data, we cannot assess the potential non-linear patterns of brain changes that may arise throughout the illness, particularly in the context of a changeable clinical picture. Third, it is important to consider the heterogeneity of MDD. Different types of depressive episodes, such as psychotic, melancholic, atypical, or early and late onset can be associated with reduction or increase in cortical thickness. In conclusion, our results suggest that cortical thickness might be normal at least in some untreated first-episode MDD patients.

To date, only two SBM studies examined the wholebrain cortical surface area in untreated first-episode MDD patients. Similar to our findings, one previous study found no differences between untreated firstepisode MDD patients with HC (11) while a recent study found an increased surface area in patients with MDD relative to $\mathrm{HC}$ in areas including the right isthmus cingulate region, right superior frontal region, and left inferior parietal region, while a decreased surface area in patients with MDD was observed in areas including the left transverse temporal region and the right inferior parietal region (21). Further studies are required to assess surface area abnormalities at various stages of MDD.

The hippocampus is the most commonly examined subcortical region in previous MDD studies and 
hippocampal volume alterations seems to occur most commonly in recurrent or early-onset MDD patients. For example, a recent ENIGMA study with 1728 MDD patients, both first-episode and recurrent, and 7199 healthy controls reported lower mean hippocampal volume in recurrent episode MDD patients but not in first-episode MDD patients. The same study also found hippocampal volume reductions were more pronounced in early-onset patients $(<21$ years) but not in late-onset patients ( $>21$ years) (27). In line with this, two recent studies with untreated first-episode patients with MDD older than 21 years also did not find any difference in hippocampal volume compared to HC $(22,26)$. Given that the patients in this study were also late-onset patients with MDD, it seems that hippocampal volume reduction is not present in MDD, at least in medication-free, late-onset first-episode patients.

Apart from the hippocampus, in line with our findings a recent ENIGMA study did not detect any significant volume differences between first-episode patients and healthy controls in subcortical gray matter regions including the nucleus accumbens, amygdala, caudate, pallidum, putamen and thalamus (27). The finding of normal amygdala volumes in first-episode, untreated patients with MDD is in contrast with previous studies that found amygdala volume alterations in first-episode patients with $\operatorname{MDD}(7,55,56)$. However, recent studies using FreeSurfer did not find any differences in amygdala volume in first-episode patients with MDD compared to HC $(22,24,26,27)$. Unfortunately, subcortical structures other than hippocampus and amygdala are not well studied in first-episode patients with MDD. One recent study found smaller volumes in both thalamus and putamen (26), but studies using FreeSurfer did not replicate these results $(22,24,27)$. Therefore, inconsistencies across studies might be due to different software used for analysis.

The findings of this study should be interpreted after consideration of the following limitations. First, this study was cross-sectional in design, which did not allow us to elucidate the temporal relationships between MDD and brain alterations. Second, the sample size limited the strength of the findings and did not give any opportunity to examine the depression subtypes.

In conclusion, this study provides evidence that cortical thickness, cortical surface area, and subcortical volumes might be normal in first-episode untreated patients with MDD in comparison with well-matched controls, particularly for BMI and smoking status.

\begin{tabular}{|l|l|l|}
\hline \multicolumn{2}{|l|}{ Contribution Categories } & Author Initials \\
\hline \multirow{4}{*}{ Category 1} & Concept/Design & D.H.D., N.Z., E.B., Z.H.A. \\
\cline { 2 - 3 } & Data acquisition & D.H.D., P.K.Z., E.P.B., Z.H.A. \\
\cline { 2 - 3 } & Data analysis/Interpretation & D.H.D., E.B., N.Z. \\
\hline \multirow{2}{*}{ Category 2} & Drafting manuscript & D.H.D., P.K.Z., E.P.B., Z.H.A. \\
\cline { 2 - 3 } & Critical revision of manuscript & N.Z., E.B. \\
\hline \multirow{2}{*}{ Category 3} & Final approval and accountability & $\begin{array}{l}\text { D.H.D., P.K.Z., E.P.B., E.B., } \\
\text { Z.H.A., N.Z. }\end{array}$ \\
\hline \multirow{2}{*}{ Other } & Technical or material support & D.H.D., Z.H.A., P.K.Z., E.P.B. \\
\cline { 2 - 3 } & Supervision & N/A \\
\hline
\end{tabular}

Ethics Committee Approval: This study was approved by the local research and Ethics Committee.

Informed Consent: Written informed consent was obtained from the patients.

Peer-review: Externally peer-reviewed.

Conflict of Interest: Authors declared no conflict of interest.

Financial Disclosure: Authors declared no financial support.

\section{REFERENCES}

1. Kessler RC, Angermeyer M, Anthony JC, DE Graaf R, Demyttenaere K, Gasquet I, DE Girolamo G, Gluzman S, Gureje O, Haro JM, Kawakami N, Karam A, Levinson D, Medina Mora ME, Browne MO, Posada-Villa J, Stein DJ, Adley Tsang $\mathrm{CH}$, Aguilar-Gaxiola S, Alonso J, Lee S, Heeringa S, Pennell, B, Berglund P, Gruber MJ, Petukhova M, Chatterji S, Ustun TB. Lifetime prevalence and age-of-onset distributions of mental disorders in the World Health Organization's World Mental Health Survey Initiative. World Psychiatry 2007; 6:168-176.

2. Eyre H, Baune BT. Neuroplastic changes in depression: a role for the immune system. Psychoneuroendocrinology 2012; 37:13971416 .

3. Durmusoglu E, Ugurlu O, Akan S, Simsek F, Kizilates G, Kitis O, Ozkul BA, Eker MC, Coburn KL, Gonul AS. Hippocampal shape alterations in healthy young women with familial risk for unipolar depression. Compr Psychiatry 2018; 82:7-13.

4. Ozalay O, Calli C, Kitis O, Cagdas Eker M, Donat Eker O, Ozan E, Coburn KL, Gonul AS. The relationship between the anterior corpus callosum size and prefrontal cortex volume in drug-free depressed patients. J Affect Disord 2013; 146:281-285.

5. Arnone D, Job D, Selvaraj S, Abe O, Amico F, Cheng Y, Colloby SJ, O’Brien JT, Frodl T, Gotlib IH, Ham BJ, Kim MJ, Koolschijn PC, Perico CA, Salvadore G, Thomas AJ, Van Tol MJ, van der Wee NJ, Veltman DJ, Wagner G, McIntosh AM. Computational meta-analysis of statistical parametric maps in major depression. Hum Brain Mapp 2016; 37:1393-1404.

6. Bora E, Harrison BJ, Davey CG, Yucel M, Pantelis C. Metaanalysis of volumetric abnormalities in cortico-striatal-pallidalthalamic circuits in major depressive disorder. Psychol Med 2012; 42:671-681.

7. Bora E, Fornito A, Pantelis C, Yucel M. Gray matter abnormalities in Major Depressive Disorder: a meta-analysis of voxel based morphometry studies. J Affect Disord 2012; 138:9-18. 
8. Koolschijn PC, van Haren NE, Lensvelt-Mulders GJ, Hulshoff Pol HE, Kahn RS. Brain volume abnormalities in major depressive disorder: a meta-analysis of magnetic resonance imaging studies. Hum Brain Mapp 2009; 30:3719-3735.

9. Videbech P, Ravnkilde B. Hippocampal volume and depression: a meta-analysis of MRI studies. Am J Psychiatry 2004; 161:19571966.

10. Schmaal L, Hibar DP, Samann PG, Hall GB, Baune BT, Jahanshad N, Cheung JW, van Erp TGM, Bos D, Ikram MA, Vernooij MW, Niessen WJ, Tiemeier H, Hofman A, Wittfeld K, Grabe HJ, Janowitz D, Bulow R, Selonke M, Volzke H, Grotegerd D, Dannlowski U, Arolt V, Opel N, Heindel W, Kugel H, Hoehn D, Czisch M, Couvy-Duchesne B, Renteria ME, Strike LT, Wright MJ, Mills NT, de Zubicaray GI, McMahon KL, Medland SE, Martin NG, Gillespie NA, Goya-Maldonado R, Gruber O, Kramer B, Hatton SN, Lagopoulos J, Hickie IB, Frodl T, Carballedo A, Frey EM, van Velzen LS, Penninx BWJH, van Tol MJ, van der Wee NJ, Davey CG, Harrison BJ, Mwangi B, Cao B, Soares JC, Veer IM, Walter H, Schoepf D, Zurowski B, Konrad C, Schramm E, Normann C, Schnell K, Sacchet MD, Gotlib IH, MacQueen GM, Godlewska BR, Nickson T, McIntosh AM, Papmeyer M, Whalley HC, Hall J, Sussmann JE, Li M, Walter M, Aftanas L, Brack I, Bokhan NA, Thompson PM, Veltman DJ. Cortical abnormalities in adults and adolescents with major depression based on brain scans from 20 cohorts worldwide in the ENIGMA Major Depressive Disorder Working Group. Mol Psychiatry 2017; 22:900-909.

11. Qiu L, Lui S, Kuang W, Huang X, Li J, Li J, Zhang J, Chen H, Sweeney JA, Gong Q. Regional increases of cortical thickness in untreated, first-episode major depressive disorder. Transl Psychiatry 2014; 4:e378.

12. Reynolds S, Carrey N, Jaworska N, Langevin LM, Yang XR, Macmaster FP. Cortical thickness in youth with major depressive disorder. BMC Psychiatry 2014; 14:83.

13. Lim HK, Jung WS, Ahn KJ, Won WY, Hahn C, Lee SY, Kim I, Lee CU. Regional cortical thickness and subcortical volume changes are associated with cognitive impairments in the drug-naive patients with late-onset depression. Neuropsychopharmacology 2012; 37:838-849.

14. Mackin RS, Tosun D, Mueller SG, Lee JY, Insel P, Schuff N, Truran-Sacrey D, Arean P, Nelson JC, Weiner MW. Patterns of reduced cortical thickness in late-life depression and relationship to psychotherapeutic response. Am J Geriatr Psychiatry 2013; 21:794-802.

15. van Tol MJ, Li M, Metzger CD, Hailla N, Horn DI, Li W, Heinze HJ, Bogerts B, Steiner J, He H, Walter M. Local cortical thinning links to resting-state disconnectivity in major depressive disorder. Psychol Med 2014; 44:2053-2065.

16. Lan MJ, Chhetry BT, Oquendo MA, Sublette ME, Sullivan G, Mann JJ, Parsey Rv. Cortical thickness differences between bipolar depression and major depressive disorder. Bipolar Disord 2014; 16:378-388.

17. Taylor WD, Boyd B, McQuoid DR, Kudra K, Saleh A, MacFall JR. Widespread white matter but focal gray matter alterations in depressed individuals with thoughts of death. Prog Neuropsychopharmacol Biol Psychiatry 2015; 62:22-28.
18. Du MY, Wu QZ, Yue Q, Li J, Liao Y, Kuang WH, Huang XQ, Chan RC, Mechelli A, Gong QY. Voxelwise meta-analysis of gray matter reduction in major depressive disorder. Prog Neuropsychopharmacology Biol Psychiatry 2012; 36:11-16.

19. Papmeyer M, Giles S, Sussmann JE, Kielty S, Stewart T, Lawrie SM, Whalley HC, McIntosh AM. Cortical thickness in individuals at high familial risk of mood disorders as they develop major depressive disorder. Biol Psychiatry 2015; 78:58-66.

20. van Eijndhoven P, van Wingen G, Katzenbauer M, Groen W, Tepest R, Fernandez G, Buitelaar J, Tendolkar I. Paralimbic cortical thickness in first-episode depression: evidence for traitrelated differences in mood regulation. Am J Psychiatry 2013; 170:1477-1486.

21. Peng D, Shi F, Li G, Fralick D, Shen T, Qiu M, Liu J, Jiang K, Shen D, Fang Y. Surface vulnerability of cerebral cortex to major depressive disorder. PLoS One 2015; 10(3):e0120704.

22. Zhao K, Liu H, Yan R, Hua L, Chen Y, Shi J, Yao Z, Lu Q. Altered patterns of association between cortical thickness and subcortical volume in patients with first episode major depressive disorder: a structural MRI study. Psychiatry Res Neuroimaging 2017; 260:16-22.

23. Liu X, Kakeda S, Watanabe K, Yoshimura R, Abe O, Ide S, Hayashi K, Katsuki A, Umeno-Nakano W, Watanabe R, Ueda I, Moriya J, Nakamura J, Korogi Y. Relationship between the cortical thickness and serum cortisol levels in drug-naive, firstepisode patients with major depressive disorder: a surface-based morphometric study. Depress Anxiety 2015; 32:702-708.

24. Han KM, Choi S, Jung J, Na KS, Yoon HK, Lee MS, Ham BJ. Cortical thickness, cortical and subcortical volume, and white matter integrity in patients with their first episode of major depression. J Affect Disord 2014; 155:42-48.

25. Cole J, Costafreda SG, McGuffin P, Fu CH. Hippocampal atrophy in first episode depression: a meta-analysis of magnetic resonance imaging studies. J Affect Disord 2011; 134:483-487.

26. Lu Y, Liang H, Han D, Mo Y, Li Z, Cheng Y, Xu X, Shen Z, Tan C, Zhao W, Zhu Y, Sun X. The volumetric and shape changes of the putamen and thalamus in first episode, untreated major depressive disorder. Neuroimage Clin 2016; 11:658-666.

27. Schmaal L, Veltman DJ, van Erp TG, Samann PG, Frodl T, Jahanshad N, Loehrer E, Tiemeier H, Hofman A, Niessen WJ, Vernooij MW, Ikram MA, Wittfeld K, Grabe HJ, Block A, Hegenscheid K, Volzke H, Hoehn D, Czisch M, Lagopoulos J, Hatton SN, Hickie IB, Goya-Maldonado R, Kramer B, Gruber O, Couvy-Duchesne B, Renteria ME, Strike LT, Mills NT, de Zubicaray GI, McMahon KL, Medland SE, Martin NG, Gillespie NA, Wright MJ, Hall GB, MacQueen GM, Frey EM, Carballedo A, van Velzen LS, van Tol MJ, van der Wee NJ, Veer IM, Walter H, Schnell K, Schramm E, Normann C, Schoepf D, Konrad C, Zurowski B, Nickson T, McIntosh AM, Papmeyer M, Whalley HC, Sussmann JE, Godlewska BR, Cowen PJ, Fischer FH, Rose M, Penninx BW, Thompson PM, Hibar DP. Subcortical brain alterations in major depressive disorder: findings from the ENIGMA Major Depressive Disorder working group. Mol Psychiatry 2016; 21:806-812.

28. Quek Y-H, Tam WWS, Zhang MWB, Ho RCM. Exploring the association between childhood and adolescent obesity and depression: a meta-analysis. Obes Rev 2017; 18:742-754. 
29. Yang JL, Liu DX, Jiang H, Pan F, Ho CS, Ho RC. The effects of high-fat-diet combined with chronic unpredictable mild stress on depression-like behavior and Leptin/LepRb in male rats. Sci Rep 2016; 6:35239.

30. Mak K-K, Ho RC-M, Day JR. The associations of asthma symptoms with active and passive smoking in Hong Kong adolescents. Respir Care 2012; 57:1398-1404.

31. Lu Y, Van Bever HPS, Lim TK, Kuan W Sen, Goh DYT, Mahadevan M, Sim TB, Ho R, Larbi A, Ng TP. Obesity, asthma prevalence and IL-4: roles of inflammatory cytokines, adiponectin and neuropeptide Y. Pediatr Allergy Immunol 2015; 26:530-536.

32. Lu Y, Ho R, Lim TK, Kuan WS, Goh DY, Mahadevan M, Sim TB, Van Bever HP, Larbi A, Ng TP. Neuropeptide Y may mediate psychological stress and enhance $\mathrm{TH} 2$ inflammatory response in asthma. J Allergy Clin Immunol 2015; 135:10611063.e4.

33. de Wit L, Luppino F, van Straten A, Penninx B, Zitman F, Cuijpers P. Depression and obesity: a meta-analysis of community-based studies. Psychiatry Res 2010; 178:230-235.

34. Pratt LA, Brody DJ. Depression and smoking in the U.S. household population aged 20 and over, 2005-2008. NCHS Data Brief 2010; 34 .

35. Zorlu N, Cropley VL, Zorlu PK, Delibas DH, Adibelli ZH, Baskin EP, Esen OS, Bora E, Pantelis C. Effects of cigarette smoking on cortical thickness in major depressive disorder. J Psychiatr Res 2017; 84:1-8.

36. Opel N, Redlich R, Grotegerd D, Dohm K, Heindel W, Kugel H, Arolt V, Dannlowski U. Obesity and major depression: bodymass index (BMI) is associated with a severe course of disease and specific neurostructural alterations. Psychoneuroendocrinology 2015; 51:219-226.

37. Franklin TR, Wetherill RR, Jagannathan K, Johnson B, Mumma J, Hager N, Rao H, Childress AR. The effects of chronic cigarette smoking on gray matter volume: influence of sex. PLoS One 2014; 9:e104102.

38. Hanlon CA, Owens MM, Joseph JE, Zhu X, George MS, Brady KT, Hartwell KJ. Lower subcortical gray matter volume in both younger smokers and established smokers relative to nonsmokers. Addict Biol 2016; 21:185-195.

39. First MB, Spitzer RL, Gibbon M, Williams JBW. Structured Clinical Interview For DSM-IV Axis I Disorders (SCID-I), Clinical Version. Washington D.C. and London: American Psychiatric Press, 1997.

40. Hamilton MA. Rating scale for depression. J Neurol Neurosurg Psychiatry 1960; 23:56-62.

41. Akdemir A, Turkcapar MH, Orsel SD, Demirergi N, Dag I, Ozbay MH. Reliability and validity of the Turkish version of the Hamilton Depression Rating Scale. Compr Psychiatry 2001; 42:161-165.

42. Fagerström KO. Measuring degree of physical dependence to tobacco smoking with reference to individualization of treatment. Addict Behav 1978; 3:235-241.
43. Uysal MA, Kadakal F, Karsidag C, Bayram NG, Uysal O, Yilmaz V. Fagerström test for nicotine dependence: reliability in a Turkish sample and factor analysis. Tuberculosis and Thorax 2004; 52:115-121.

44. Dale AM, Fischl B, Sereno MI. Cortical Surface-Based Analysis: I. Segmentation and Surface Reconstruction. Neuroimage 1999; 9:179-194.

45. Fischl B, Sereno MI, Dale AM. Cortical Surface-Based Analysis: II. Inflation, flattening, and a surface-based coordinate system. Neuroimage 1999; 9:195-207.

46. Fischl B, Dale AM. Measuring the thickness of the human cerebral cortex from magnetic resonance images. Proc Natl Acad Sci USA 2000; 97:11050-11055.

47. Zaremba D, Dohm K, Redlich R, Grotegerd D, Strojny R, Meinert S, Redlich R, Grotegerd D, Strojny R, Meinert S, Bürger C, Enneking V, Förster K, Repple J, Opel N, Baune BT, Zwitserlood P, Heindel W, Arolt V, Kugel H, Dannlowski U. Association of brain cortical changes with relapse in patients with major depressive disorder. JAMA Psychiatry 2018; 75:484492.

48. Pardoe HR, Abbott DF, Jackson GD. Sample size estimates for well-powered cross-sectional cortical thickness studies. Hum Brain Mapp 2013; 34:3000-3009.

49. Habets P, Marcelis M, Gronenschild E, Drukker M, van Os J, Genetic Risk and Outcome of Psychosis (G.R.O.U.P). Reduced cortical thickness as an outcome of differential sensitivity to environmental risks in schizophrenia. Biol Psychiatry 2011; 69:487-494.

50. Kuhn S, Schubert F, Gallinat J. Reduced thickness of medial orbitofrontal cortex in smokers. Biol Psychiatry 2010; 68:10611065.

51. Li Y, Yuan K, Cai C, Feng D, Yin J, Bi Y, Shi S, Yu D, Jin C, von Deneen KM, Qin W, Tian J. Reduced frontal cortical thickness and increased caudate volume within fronto-striatal circuits in young adult smokers. Drug Alcohol Depend 2015; 151:211-219.

52. Karama S, Ducharme S, Corley J, Chouinard-Decorte F, Starr JM, Wardlaw JM, Bastin ME, Deary IJ. Cigarette smoking and thinning of the brain's cortex. Mol Psychiatry 2015; 20:778-785.

53. Veit R, Kullmann S, Heni M, Machann J, Haring HU, Fritsche A, Preissl $\mathrm{H}$. Reduced cortical thickness associated with visceral fat and BMI. Neuroimage Clin 2014; 6:307-311.

54. Medic N, Ziauddeen H, Ersche KD, Farooqi IS, Bullmore ET, Nathan PJ, Ronan L, Fletcher PC. Increased body mass index is associated with specific regional alterations in brain structure. Int J Obes (Lond) 2016; 40:1177-1182.

55. van Eijndhoven $P$, van Wingen $G$, van Oijen $K$, Rijpkema $M$, Goraj B, Jan Verkes R, Oude Voshaar R, Fernandez G, Buitelaar J, Tendolkar I. Amygdala volume marks the acute state in the early course of depression. Biol Psychiatry 2009; 65:812-818.

56. Frodl T, Meisenzahl E, Zetzsche T, Bottlender R, Born C, Groll C, Jager M, Leinsinger G, Hahn K, Moller HJ. Enlargement of the amygdala in patients with a first episode of major depression. Biol Psychiatry 2002; 51:708-714. 